DE ECONOMIST 157, NO. 2, 2009

\title{
AGENDA FOR THE HOUSING MARKET
}

BY

\author{
HENK DON*
}

\section{Summary}

\begin{abstract}
The housing market is the theme of the Reports to the 2008 Annual Meeting of the Royal Netherlands Economic Association. Current housing market policies in the Netherlands generate substantial welfare losses. The direct and indirect subsidies on housing distort the housing market, house moving behaviour, the labour market and the asset portfolio of households. The welfare loss is estimated at more than 6 billion euro per year. In addition, physical planning restrictions cost at least 3 billion euro per year, a price which is paid for the conservation of open space and nature, especially in the Green Heart of the Randstad. Developments on the housing market over the last fifteen years and the sizeable welfare losses from current policies are sufficient reason to develop an agenda for reform. The Reports suggest several elements for such an agenda, including a gradual reduction of housing subsidies in the owner-occupier sector as well as in the rental sector, an easier land policy to better meet the qualitative housing needs of the population, and an extension of the social tasks for the housing societies.
\end{abstract}

Key words: housing societies, housing subsidies, land policy, physical planning

JEL Code(s): D61, E64, L85, R52

\section{INTRODUCTION}

This communication gives an overview of the Reports to the 2008 Annual Meeting of the Royal Netherlands Economic Association (Don (2008)). The theme of the 2008 Reports is the housing market in the Netherlands. As in most countries, the government interferes heavily with the housing market through rules and regulations as well as through subsidies and taxes. The Reports provide a critical review of the motives for and forms of government interference. They highlight the associated welfare costs, both in the housing market and in related areas like the labour market, household financial portfolios and agglomeration dynamics. Future housing demand is assessed and the future role of the housing societies is discussed. Several options for policy reform are put forward and some of them are examined for their macroeconomic impact.

* Corresponding author: Econometric Institute, Erasmus University Rotterdam, Room H11-09, P.O. Box 1738, 3000 DR Rotterdam, The Netherlands; e-mail: don@ese.eur.nl 
Section 2 provides some background to the Reports and includes a brief sketch of recent developments and current problems in the housing market. Section 3 summarizes each of the six Reports. Section 4 draws some conclusions which aim to contribute to developing a realistic agenda for policy reform.

\section{BACKGROUND}

The housing market has been the subject of much debate in the Netherlands over the last few years. To a large extent this was the unintended result of government decisions. The political deal between the current coalition parties not to prepare or even investigate any change in the tax treatment of owneroccupied housing during the present cabinet term rather stimulated the public debate and encouraged independent research. The conflict with the housing societies over their contribution to the program for reinvigorating the most vulnerable problematic neighbourhoods has put the spot-lights on the mismatch between social responsibilities and formal governance in that sector. In response to the broadening of the corporation tax base, some housing societies are considering whether and on what terms they can leave the system. This has made questions about command and ownership of the large net wealth of the societies more urgent.

Developments on the housing market in the Netherlands over the last fifteen years also give ample reason for reconsideration of its institutional setting. Market prices for houses have risen strongly and much faster than construction costs for new homes (see Figure 1). This has caused a widening of the gap between the rental sector and the owner-occupier sector, as well as an increase in insider/outsider-problems in both sectors.

The rental sector is dominated by the housing societies, which can ask relatively low rents because they have no need to make market rates of return on their large equity capital (valuing their houses at market prices) - a private equity would see golden opportunities. In addition many tenants are entitled to a rent allowance from the government. As a result, net housing costs in the rental sector are far below market rates. New entrants often have difficulty finding a home, because in many municipalities the housing societies have long waiting lists for low-rent homes. Tenants are not inclined to move, also if they no longer belong to the target group of the housing societies. The private rental sector cannot offer a comparable quality/price ratio and houses in the owner-occupier sector have also become comparatively expensive (see again Figure 1).

In the owner-occupier sector, enormous capital gains in the market value of their homes have accrued to the insiders. The tax subsidies to 


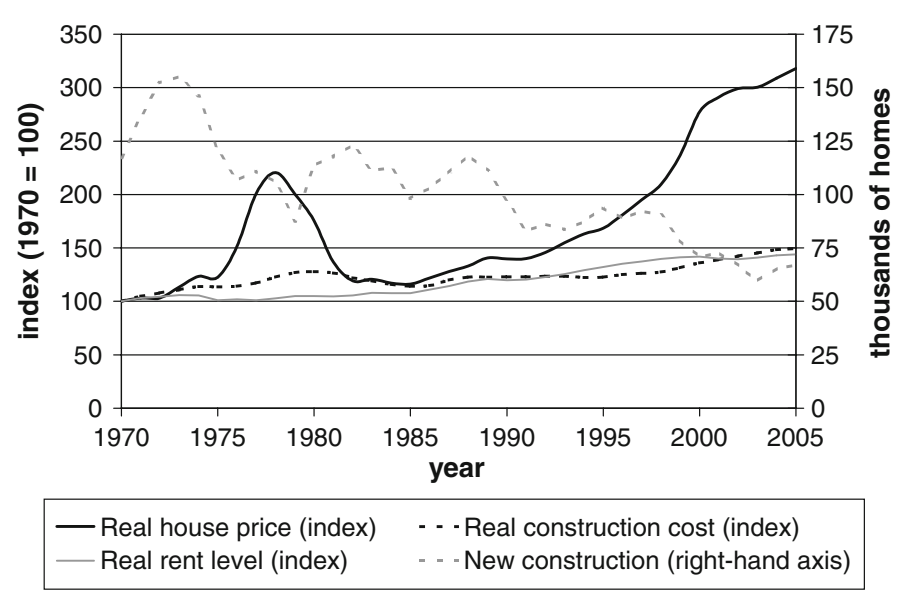

Figure 1 - House price, rent level, construction cost and new construction in the Netherlands, 1970-2005. Source: CPB

owner-occupiers ${ }^{1}$ have grown fast in money terms and are sensitive to house prices and mortgage interest rates. At the same time the high prices imply that the owner-occupier sector has become almost inaccessible to outsiders (entrants on the housing market and renters), unless they have a substantial capital or a high income. Yet a further analysis shows that affordability of owner-occupied houses has not changed much over the period 1985-2005 (Renes et al. (2006)). This fits in with the conclusion that the strong increase in house prices was largely caused by the determinants of housing demand, i.e. growing income, growing wealth and decreasing interest rates. Housing supply does not or hardly respond to the strength of demand, though investment in the quality of houses has definitely increased. The elasticity of supply is constrained in particular by physical planning regulations. The resulting scarcity premium largely flows to the owners of the land, often municipalities or owner-occupiers, for whom a larger premium does not act as an incentive to build more or higher quality houses.

What are the detrimental effects of the current housing market regime?

To an economist, the first loss is the suboptimal allocation of scarce resources: due to the massive direct and indirect subsidization too much is spent on housing, i.e. the marginal social benefit is smaller than the marginal social cost. Only a small part of the subsidies can be justified as a correction

1 These tax subsidies are mainly determined by the net effect of (i) mortgage interest deduction at the progressive tax rate applicable to labour income; (ii) the low imputed rent income which is taxed at the same progressive rate; (iii) the $6 \%$ transfer tax on any house resale; (iv) exemption of the value of the house (net of mortgage debt) from the flat tax on imputed return to net assets. 
to market outcomes, viz. where social interests are insufficiently reflected in purchasing power. Because the larger part of the subsidies is funded by taxes, they lead to higher tax rates with all the concomitant distortions.

Next, there are all kinds of improper impediments to house moving, both in the rental sector (rent protection and regulation, waiting lists) and in the owner-occupier sector (transfer tax). As a result, also the allocation within the housing market is suboptimal. And finally the current housing market regime has negative side effects on other markets: impediments to house moving also distort the allocation on the labour market and the tax treatment of owner-occupied houses distorts the financial portfolio decisions of homeowners, because it favours mortgage debt over equity for financing the house.

Recently many researchers have studied the functioning of the housing market and its effects on other markets; the Reports draw heavily on these and add some new results themselves. The Dutch Council of Economic Advisors (REA (2006)) and the Dutch Council for Housing, Spatial Planning and the Environment (VROM-raad (2007)) have published advisory reports. Policy recommendations have also been formulated in some research studies. The Committee of Social and Economic Experts of the Social and Economic Council is working on an exploratory study. Opinions differ as to what a proper housing market regime should look like. If an agreement would be reached on the long term target, then it would still be difficult to find a practicable way to get there. Next to public interests the housing market affects large private interests (vested interests) which can obstruct change.

The ambition of the collected Reports to the 2008 Annual Meeting of the Royal Netherlands Economic Association is to suggest elements for a realistic agenda for the various parties on the housing market, based on up-to-date knowledge and taking into account the relevant constraints, side effects and public support.

\section{OVERVIEW OF THE REPORTS}

\subsection{Physical Planning and Redistribution}

The first Report, by Paul Besseling, Lans Bovenberg, Gerbert Romijn and Wouter Vermeulen, starts with an analysis of the arguments for government intervention on the housing market. The authors conclude that most external effects on this market cannot justify large interventions by the central government. Regulation of land use in urban areas often is better left to local authorities. Only for some issues in physical planning (open space and nature), and possibly for redistribution, the proper policy level is the national government. These two themes are then further taken up for the Netherlands and analysed in depth. 
The authors estimate that physical planning regulations in the Netherlands have a shadow price (impose a regulatory tax) which now on average amounts to about one third of the house prices. On the other hand they generate direct benefits (regulation rents) in the form of scarcity premiums and capital gains. The net welfare loss in terms of foregone consumer surplus on the housing market is estimated by the authors at 3 billion euro per year. In addition there are unknown welfare losses that flow from the fact that physical planning regulations also prevent the reaping of agglomeration benefits from further growth of cities, indirectly depress labour supply and increase the volatility of house prices. It is difficult to say whether these losses are balanced by a gain of at least the same size in the form of open space and nature - the value of the "Green Heart" of the Randstad and the buffer zones between the four big cities is hard to assess.

The redistribution which is effectuated through the housing market is quite substantial in the Netherlands: housing costs of tenants and owner-occupiers are now subsidized at a net rate of almost 29 billion euro per year, 16 billion of which comes at the expense of the central government (i.e. the tax payer) and 13 billion at the expense of the landlords (mainly housing societies). In fact this entails hardly any real redistribution between different income groups and the subsidies almost cancel the burden of the regulatory tax that is imposed on the housing costs by the physical planning regulations. But it does generate a welfare loss which the authors estimate at more than 6 billion euro per year, as a result of distorted incentives in the housing market, house moving behaviour and the labour market. In addition it generates a welfare loss of unknown size by distorting the decision to rent or buy and the decisions on the asset portfolios of private households.

Thanks to the policy regime in the rental sector, a large number of people at a low income level can live in a larger and better home than would otherwise have been the case. But perhaps they would have been better off with a form of income support which is independent of the rent they pay.

\subsection{Housing Needs and Impediments}

In the second Report, Piet Eichholtz and Thies Lindenthal provide a long term perspective, looking far back in time as well as far into the future. Looking back until 1550 they show that the increase in real housing rents that has occurred over the last decades is an exception in a long historical perspective. Also in an international comparison the house prices in the Netherlands are exceptional. In explanation the authors point to the impediments for housing supply which resulted from physical planning restrictions, from an overemphasis on social housing in building projects, and from the growing delays caused by bureaucratic procedures and democratic participation before a building project can go ahead. Despite their complaints, hous- 
ing societies and project developers in fact often do not really have an interest in faster procedures or limits to participation: to a large extent the rents of scarcity flow to them and the local municipalities. Thus the parties that determine actual construction volumes lack a strong incentive to reduce the delays.

Looking into the future, the authors focus on the prospective demand for housing. This cannot be simply derived from a population or household forecast. From their own research on a large and detailed set of microdata for the $\mathrm{UK}$, the authors conclude that human capital is the key determinant of the demand for housing. Application to the Netherlands indicates a continuing growth of housing demand until 2050, though at a slower pace after 2030. Probably the hypothesis that elderly people consume less space will cease to hold in the future, hence replacement investments will also be required. The official forecasts used by the Ministry of Housing, Spatial Planning and the Environment systematically underestimate the demand for housing that should really be expected. It is true that more second homes than before will be located abroad, but within the national borders elderly people will move from the Randstad to the provinces of Flevoland, Drenthe, Friesland and Zeeland.

The uncertainty in demographics, household formation and housing needs calls for maximum flexibility of housing supply. The taste of Dutch citizens for single family homes with a garden is at odds with the taste of policy makers for large scale high risers within current city borders.

An affordable housing market requires an easier land policy, redestining much more agricultural land for residential purposes. The farmers' organisations can perhaps go along if the profits of redestination do not fall to the small group that sells its land, but to the farmers collectively. To speed up housing production, the central government should arrange for shorter procedures and less scope for appeals.

The apparent shortage of low-rent social housing should not be solved by building more for the housing societies, but by improving the stream of reallocations. If rent liberalisation is a bridge too far, then a strict system of means testing should ensure that those who can afford it pay a normal market rent for their home.

\subsection{Housing and Work}

The third Report, by Frank van Oort, Thomas de Graaff, Gusta Renes and Mark Thissen, studies the connections between the economic dynamics and the housing market in the Randstad. In the Northern wing of the Randstad, business, financial and creative services get all the space they need, but the supply of high-quality housing for the concomitant workers stays far behind. This may harm the economic development. The tension generates a 
regional premium on the house prices, referred to as a scarcity premium by the authors. ${ }^{2}$ The scarcity premiums are high in the Randstad, especially in and near Utrecht and Amsterdam. These areas are characterized by relatively high economic growth nearby and a relatively low growth of the housing stock.

The rental sector is quite large in the urban areas of (greater) Rotterdam, (greater) Amsterdam, Utrecht and The Hague. The system of rent control allows only rent increases based on inflation or cost indices, ignoring the agglomeration benefits which generate higher economic growth in the urban centres. Hence the gap between the rental and the owner-occupier sectors is particularly visible in the Randstad. The shortage of houses for sale induces households to stay in a regulated rental house, even if their income rises. This is comparatively most common in (greater) Amsterdam and (greater) Rotterdam. The result is an inefficient allocation of public funds.

The dynamics of housing and work is a simultaneous process. In a model for the Randstad, the largest effects are those from growth in the labour force to employment growth in the education, retail trade and government sectors, and to a lesser extent in the business services industry. Also, population growth follows growth of the former sectors. While in other countries one finds that "housing follows work" as well as "work follows housing", the dynamic pattern in the Netherlands tends to be different. This is due to the fact that the Netherlands has many restrictions on the choice of a housing location, especially in the Randstad. In the Randstad, the development of housing locations leads to additional employment; if housing construction were neglected in the Randstad, then in the long run employment growth would suffer.

The authors conclude that a stronger coordination of housing policies and employment policies could better exploit the economic potential of the urban regions. To promote economic growth, agglomeration benefits of the Randstad should be better facilitated through the construction of houses for the higher income groups, in particular in the Northern wing. The physical planning policy to safeguard the Green Heart against building activities, hampers the engine for economic growth.

\subsection{The Housing Societies}

What are we going to do with the housing societies? This is the question discussed in the fourth Report, by Annet Bertram and Jan-Kees Helderman. They show how politicians have increasingly lost trust in the housing

2 In the other (sub)sections, the scarcity premium is defined as the difference between the market price of new houses and all costs that had to be made in building it. 
societies after they became less dependent on government both financially and formally in 1992. The loss of trust is explained by doubts about performance, poor supervision, high salaries and large and fast increasing net assets of the housing societies. Along different lines, successive ministers have tried to define clearer relations with the housing societies, with mixed results. Of present interest are the intense debate on the program for reinvigorating the most vulnerable problematic neighbourhoods (who will pay?) and the legalfinancial position of the housing societies and their assets (is it possible and reasonable to levy corporation tax on their core business? can a housing society leave the system?).

The debate about the proper functioning of the housing market is mainly triggered by questions about the efficiency of the large subsidies and by problems in the regions where demand is well in excess of supply. The authors note that none of the established parties on the housing market (owner-occupiers, housing societies, municipalities, builders) has an interest in reduction of the tax deductibility of mortgage interest. In regions where the housing market is tight, a liberalisation of housing rents will lead to a further growth of the net wealth of the housing societies. This adds to the importance of the question how this social capital is allocated. Legally the unequivocal answer is housing, but this can get a liberal interpretation. The governance structure is vulnerable to undermining by processes that pull it too far towards government, towards the market and/or away from its civic basis.

Quite separate from these discussions, parties at the local level have managed to forge coalitions for reinvigorating the most vulnerable neighbourhoods. Here the housing societies play a crucial role because, together with the schools, they have unique knowledge of local circumstances and the situation of vulnerable families. Using recent practical experience from the municipality of The Hague, the authors show how the traditional housing tasks are supplemented by concrete actions to improve living conditions, health (especially for young people), problem families, naturalisation and the neighbourhood economy. These actions also involve other social organisations. The municipality regains coordination and supervision, after a long period of control by central government.

This opens a perspective on a package of social tasks that can grow to include several sectors. The housing societies are in a position to take a leading role, they have the know-how and the capital to reach beyond the tasks they have taken up so far. Not further away from the government as more or less independent enterprises, but clearly semi-public with a broad social task. The authors sketch a step-by-step program to help realize this ideal and to help the parties involved transform themselves. After an experimental phase and a sound evaluation, the final step is adjustment of the legal structures. 


\subsection{Reducing and Rebuilding Subsidies}

In the fifth Report, Johan Conijn focuses on the role of consumption subsidies on the housing market. His analysis of the motives, size and impact of the subsidies starts from the public interests and market failures that have been identified in the literature. The affordability of housing proves to be the central theme; there is no reason for the government to intervene in the choice between renting and buying.

To assess the size of current subsidies, Conijn determines a subsidy-free point of reference which reflects the price of a housing service without subsidies in a balanced market. This leads him to a smaller estimate of the size of subsidies than the one used by Besseling et al. in the second Report, which is derived from Romijn and Besseling (2008). Because the subsidies in the owner-occupier sector force house prices up, they also force up the free market value of rental houses, which in the approach of Romijn and Besseling yields a higher estimate of the implicit subsidies resulting from rent regulation and the rent policies of the housing societies. Starting from the subsidy-free point of reference, subsidies in the rental sector are almost $40 \%\left(5^{1 / 2}\right.$ billion euro) smaller than in the calculations of Romijn and Besseling. This line of thought reveals an important interaction between the market for owner-occupied houses and the market for rental houses. In the owner-occupier sector subsidies force up prices by about $20 \%$, while subsidies in the rental sector force down the prices of (occupied!) rental houses. The latter effect can grow as large as $80 \%$ on the assumption that the current tenants will stay for the rest of the expected life of the house. The housing societies protect the renters against the price-raising effect of subsidies in the owner-occupier sector and against arbitrage by landlords who can make profits when houses move from the rental sector to the owner-occupier sector. As long as owner-occupiers benefit from tax subsidies, a market rate for rents would imply that the tax benefit of owner-occupiers leads to a loss for the renters.

After analysing the current regime, Conijn discusses the framework and direction for a reduction of current housing subsidies, which he characterizes as a waste of money. He points out that many other advisory reports have paid no or insufficient attention to the affordability problem and its variation over locations and circumstances. The advice of the VROM-raad puts affordability first, but it leaves the current (implicit) subsidies in the rental sector largely unaffected.

Adopting the motto "No subsidisation, unless", Conijn searches for a reduction in generic subsidies which is realistic and warrants affordability for the low-income groups. He advocates a very slow reduction of tax subsidies in the owner-occupier sector, to allow inflation help curtail the nominal losses in asset values and the associated financing problems. The additional tax revenues can be returned to the residents, partly through a reduc- 
tion of taxes and partly in the form of a specific affordability subsidy. One will also have to find a way of returning the subsidy reduction in the rental sector, which at first mainly shows up as benefits for the housing societies. In a recent experiment, the participating housing societies use the additional income from closer to market rate rents to improve affordability for the lowand medium income groups. However, it is not self-evident to expect such a return from the entire sector of housing societies.

Next to a reduction of current subsidies, a build-up of safeguards for affordability is required. In particular if the price of housing consumption in principle equals the user costs, then the need for a housing subsidy is even stronger than in the current regime. Conijn sketches some principles for a simple housing allowance, building on the current rent allowance.

\subsection{Macroeconomic Aspects}

In view of the size of the money flows and asset values involved, any change in the housing market regime will have to take the macroeconomic consequences into account. In the sixth Report, Casper van Ewijk and Harry ter Rele consider the macroeconomic aspects of the housing market. They focus on the effects of increasing - or decreasing - house prices in the Dutch situation. These effects run especially through the wealth and consumption levels of family households; the rental sector plays only a minor role.

The housing market has gained considerably in macroeconomic importance over the last few decades. The large increases in house prices in the nineties have raised the value of owner-occupied houses from $163 \%$ of annual net household income in 1980 to $439 \%$ in 2007. As a result, owner-occupied houses now account for more than half of net household wealth (including pension rights). The price increases can well be understood from the development of the determinants of housing demand - there are no indications that the 2007 prices are the result of a speculative bubble. Yet there is a risk that prices will fall; this will occur, for example, if the real interest rate rises or if incomes (are expected to) deteriorate.

In the period 1996-2002, the increase in housing wealth has contributed approximately 0.4 percentage points to the annual growth of GDP. A future decrease in house prices could have negative effects in the short and medium run. But in the long run, more precisely: for future generations, the effects of lower house prices are positive, because housing will then be cheaper.

A reduction of tax subsidies for owner-occupiers would trigger such a decrease in house prices, but also generate additional tax revenues which can be returned to the residents to mitigate the negative effects in the short and medium run. If the additional revenues are returned in a generation neutral 
way, then the result is a loss for older generations (their loss in housing wealth is larger than their gain from lower taxes) and a gain for younger and future generations (who will benefit many more years from lower taxes). Older house-owners have benefited most from past increases in house prices. And the true size of intergenerational effects of reduced tax subsidies will also depend on the consequences of lower house prices for the value of inheritances and on the impact of smaller off-balance reserves in housing societies. Also within generations large differences will occur, for instance as a result of differences in home-ownership, mortgage debt and number of children (share in inheritance).

The intergenerational differences could motivate a concomitant adjustment in government debt, which would generate fiscal room for accommodating losses in wealth of owner-occupiers. But forms of gradually reducing the tax subsidies, like discriminating between old and new home-ownership, appear to offer better targeted solutions to the transition problems.

\section{TOWARDS A REALISTIC AGENDA}

The sizeable annual losses in welfare that have been indicated by Besseling et al. are sufficient motivation for developing an agenda for reform of the housing market. The various Reports also show that drafting such an agenda is far from easy. What elements should it at least contain?

\subsection{Environment}

First it should be clear what the environment of the housing market will look like in the upcoming decades. Eichholtz and Lindenthal point out that housing demand will continue to grow until 2050, though at a smaller pace after 2030. Moreover they warn against building more low-rent social houses and observe that large-scale high risers do not match the tastes of the population.

Physical planning is also crucial for the future environment of the housing market, in particular the question whether the current boundaries of the Green Heart will be maintained. The Reports by Besseling et al. and Van Oort et al. show that these impose a large tax, which will rise further in the future. Is the Green Heart worth it? Ultimately, only politics can answer this question. But it is no coincidence that Eichholtz and Lindenthal call for an easier land policy, to better meet the qualitative housing needs of the population. Better quality housing might be preferable to a large metropolitan park at an hour away. And these need not be conflicting demands, if we are willing to literally give them more space.

In any case it is desirable to speed up house building by shortening procedures and reducing the scope for appeals. 


\subsection{Owner-Occupier Sector}

The reduction of tax subsidies in the owner-occupier sector, while returning the additional tax revenues in some way, is bound to have redistributive effects. These effects can be mitigated and spread over time in a transition period of several years and perhaps also softened by additional policy measures. It is more difficult to cushion the loss in wealth that owneroccupiers suffer because of the likely fall in house prices. An extensive transition period cannot help much to reduce this fall, as future reductions in subsidies also affect the current asset value of the house. The losses need not be a big problem for those owner-occupiers who have recorded large capital gains in the period of price increases. Recent home-owners are hit harder, though price levels may already have been depressed when they bought their house, reflecting an increasing chance of future reductions in subsidies. Targeted compensation is not simple. Van Ewijk and Ter Rele suggest to discriminate between old and new house-owners, which would imply that also elderly owner-occupiers would keep a favourable regime. Such a solution will be needed more if the decrease in house prices is not only the result of the reduction in tax subsidies, but also of an easing of physical planning restrictions. It is also conceivable to reduce the tax subsidies for old house-owners at a lower pace than for new house-owners.

At the macroeconomic level the losses in asset values will temporarily depress consumption. This reduction in demand may be compensated by simultaneous stimulation of house construction, for example through faster procedures or an easier land policy. Anyhow, a fall in house prices will also reflect less pressure of spatial demand, and hence a lower regulatory tax from physical planning restrictions and a lower scarcity premium for the landowners.

\subsection{Rental Sector}

Apart from the rent allowance, a reduction of subsidies in the rental sector is difficult because the savings do not flow to the government but largely to the housing societies. They can use them to safeguard affordability, tailored to location and circumstances. But the size and allocation of the savings that are returned are beyond (direct) control of the government. This problem is closely related to the broader debate about the position of the housing societies and the social capital under their management. Bertram and Helderman advocate an extension of the social tasks of housing societies to several sectors, in cooperation with municipalities, schools and other social organisations. Recent experience with reinvigorating vulnerable neighbourhoods provides hope for an effective approach. The financial power of the housing societies will have to match the package of tasks that is agreed upon. 
A redesign of the financial relations can also incorporate the requirements for a liberalisation of the rental sector.

Such a major operation will take several years. In the meantime the allocation on the housing market can improve if market rates are charged to those renters who do not (anymore) belong to the target group of social housing policies.

The interaction between the owner-occupier sector and the rental sector calls for a careful coordination of reforms, as is stressed by Conijn. It should be avoided that tax subsidies in the owner-occupier sector hurt the actual housing costs in the rental sector through the upward forcing of market prices.

\section{CONCLUSION}

Three years ago, I called the housing market the missing item on the reform agenda (Don (2005)). Previous research in this field had not gained much attention. In the political debate, proposals for liberalising the rental sector were set against proposals for changing the tax treatment of owner-occupied housing. Since then, the housing market has been discussed a lot and many studies and advisory reports have been published. They have also shown how complex the matter is and how close the interconnections are between the various problems on this market. This is again confirmed by the present collection of Reports. I hope it can also contribute to disentangling the knot and to developing a realistic and welfare-increasing agenda for the housing market.

Open Access This article is distributed under the terms of the Creative Commons Attribution Noncommercial License which permits any noncommercial use, distribution, and reproduction in any medium, provided the original author(s) and source are credited.

\section{REFERENCES}

Don, Henk (2005), 'Housing: The Missing Item on the Reform Agenda', CPB Newsletter, December, 1.

Don, F.J.H. (ed.) (2008), Agenda voor de woningmarkt, Preadviezen voor de Koninklijke Vereniging voor Staathuishoudkunde, KVS, Amsterdam.

REA (2006), De woningmarkt uit het slot. Over goede intenties en de harde wetten van de woningmarkt, Tweede Kamer, session 2005-2006, 30507 nr. 2.

Renes, G., M. Thissen and A. Segeren (2006), De betaalbaarheid van koopwoningen en het ruimtelijk beleid, NAi Uitgevers/RPB, Rotterdam/Den Haag. 
Romijn, G. and P.J. Besseling (2008), Economische effecten van regulering en subsidiëring van de huurwoningmarkt, CPB Document 168, CPB, Den Haag.

VROM-raad (2007), Tijd voor keuzes. Perspectief op een woningmarkt in balans. Advies 064, VROM-raad, Den Haag. 